\title{
Status of Women in Physics in Spain
}

\author{
M. Pilar López-Sancho ${ }^{\mathrm{a}}$, Margarita Chevalier ${ }^{\mathrm{b}}$, Maria J. Yzuel ${ }^{\mathrm{c}}$, \\ and Carmen Carreras ${ }^{\mathrm{d}}$
}

\author{
${ }^{a}$ Consejo Superior de Investigaciones Cientificas, Madrid; ${ }^{b}$ Universidad Complutense de Madrid, Madrid; \\ ${ }^{\circ}$ Universidad Autónoma de Barcelona, Barcelona; ${ }^{d}$ Universidad Nacional de Educación a Distancia
}

\begin{abstract}
We present activities of the group, Spanish Women in Physics, during the past three years. We describe measures adopted by the Spanish government to attain gender equality and discuss the status of women in the scientific field. Finally, we present statistical data updated from the last IUPAP Women in Physics Conference in 2005. The percentage of women at various staff levels at universities and at the Consejo Superior de Investigaciones Cientificas (CSIC) remains constant (approximately 32\%). At CSIC, however, an increase in the number of available posts has led to an increase in the number of women in top positions. The most remarkable finding from Spanish universities is that $50 \%$ of women were hired at the new professorial category of "PhD contract."
\end{abstract}

Keyw ords: women in physics, gender, science, Spain

PACS: $01.78+\mathrm{p}, 01.85 .+\mathrm{f}$

In 2005 the Spanish government adopted several gender equality measures. The Spanish parliament approved an important law in 2007 intended to ensure equality between women and men. These actions, along with recommendations from the Women in Science Unit of the European Commission, have led to a debate in a country where, for the first time, the number of women in government exceeded the number of men.

The Spanish Women in Physics group has conducted several initiatives since the last IUPAP Women in Physics Conference in 2005. The most notable include the following:

- Invitation of women to give lectures at Real Sociedad Española de Fisica (RSEF; Royal Spanish Society of Physics) conferences. Women have been included among the plenary speakers in the last three general RSEF conferences held in 2003, 2005, and 2007.

- Inclusion of sessions focused on gender issues at each RSEF conference, as well as panel discussions formed by academic authorities. Spanish Women in Physics has organized a regular session entitled "Women in Physics" to discuss problems of women working in physics.

- Increased presence of women in scientific journals. In 2006 an issue of the RSEF journal Revista Española de Fisica was dedicated to women in physics. All papers were written by women and the various sections addressed women's topics (e.g., the History section contained an article about the first female member of the Society; the Medical Physics section included an article about mammography; the section about the Society had articles about the status of women in physics in Spanish universities and public research organizations). Fifteen pictures of women physicists made up the front cover. An article, "Dimension of Gender in Physics," was included in the 2006 book, The Second Row: Gender Imbalance in Science and Technology [1].

- Inclusion of the enhanced Spanish Women in Physics website on the general RSEF website.

- Dissemination of statistical data at relevant forums.

The organization has been less successful at increasing recognition of women scientists through award nominations.

\section{STATUS OF WOMEN IN SCIENCE}

In spite of the positive actions taken by the Spanish government and Parliament, progress is slow in science. Women are underrepresented on decision-making panels ( $93 \%$ of university authorities are male scientists), and on funding and hiring commissions. In addition, women tend not to be awarded scientific prizes (or even nominated). Although problems are now recognized, solutions require constant action from the women at all institutions. By law, women must make up at least $40 \%$ of evaluation panels to hire and promote scientific personnel. However, at the university level, this percentage is reduced to $33 \%$ and $20 \%$, respectively, for recently created hiring and advisory panels. These percentages are higher in the corresponding commissions of the Consejo Superior Investigaciones

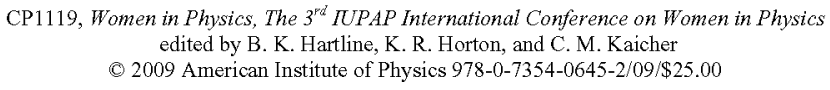


Cientifica (CSIC; Spanish Research Council). It is difficult to achieve the required ratio in the CSIC, due in part to the low number of women in some scientific fields and at some professional levels. The law has also established the number of research projects to be led by women, but we do not yet have data on this issue. It is expected that the Women in Science Unit created in 2007 will play an important role in the application of the laws.

Tables 1 and 2 give the percentage of women studying/working at levels ranging from undergraduate to Contratado Doctor at Spanish public universities in all scientific fields, and specifically in physics departments [2]. On average, $35 \%$ of the total professors are woman, a number which has remained practically constant during the last three years. This figure decreases to a $14 \%$ when the highest position (CU, "full professor") is considered, and increases to $41 \%$ at the lowest level. It is remarkable that $51 \%$ of women are at the professional level of Contratado Doctor (tenure track). The category of Permanent Professor was recently created, as the highest for the professors under contract. Data for physics professors are not complete because it is difficult to obtain statistical data for individual scientific fields. When only women are considered, $7 \%$ are at the highest-level position, while $22 \%$ of the total men are in the highest level. This makes evident the need for positive action.

TABLE 1. Percentage of Women in All Science Fields and Physics at the Undergraduate, $\mathrm{PhD}$, and Professor Levels at Spanish Public Universities in 2007 [2,3].

\begin{tabular}{lcc}
\hline Levels & All Scientific Fields & Physics \\
\hline Undergraduate & $54 \%$ & $33 \%$ \\
PhD & $49 \%$ & $15 \%$ \\
Professors: civil servants & $34 \%$ & $21 \%$ \\
Professors under contract & $37 \%$ & $24 \%$ \\
Contratado Doctor & $51 \%$ & - \\
\hline
\end{tabular}

TABLE 2. Percentage of Women in Science and Physics at Spanish Public Universities by Level $[1,2]$.

\begin{tabular}{lcc}
\hline Public Spanish Universities & All Scientific Fields & Physics \\
\hline CU - Full professors & $14 \%$ & $6 \%$ \\
TU - Assistant professors & $37 \%$ & $27 \%$ \\
CE - Professors & $33 \%$ & - \\
University & $41 \%$ & - \\
\hline
\end{tabular}

At CSIC the percentage of women at each staff level has slowly increased from 1970, with numbers staying approximately the same from 1993 to the present at the lowest levels (Table 3). The highest level has experienced the greatest increase during these years as a consequence of both the rise of the available positions and a higher number of women on hiring and promotion panels. This improvement is less in the physics, science, and technology area due in part to the low number of women in this field.

TABLE 3. Percentage of Women at Each Staff Level of CSIC for the Physics, Science, and Technology Field and the Science and Technology of Materials Field [1,3].

\begin{tabular}{lccccc}
\hline & \multicolumn{2}{c}{$\begin{array}{c}\text { Physics, Science, and } \\
\text { Technology }\end{array}$} & & \multicolumn{2}{c}{$\begin{array}{c}\text { Science and Technology } \\
\text { of Materials }\end{array}$} \\
\cline { 2 - 3 } \cline { 5 - 6 } \multicolumn{1}{c}{ Levels } & 2005 & 2007 & & 2005 & 2007 \\
\hline Professor of research & $6 \%$ & $6 \%$ & & $6 \%$ & $12 \%$ \\
Research scientist & $14 \%$ & $14 \%$ & & $46 \%$ & $38 \%$ \\
Scientist & $27 \%$ & $26 \%$ & & $40 \%$ & $43 \%$ \\
\hline
\end{tabular}

\section{REFERENCES}

1. C. Lara (ed.), El Segundo Escalón. Desequilibrios de Género en Ciencia y Tecnología, ArCiBel, 2006. (in Spanish)

2. M.P. López-Sancho, M. Chevalier, M.J. Yzuel, and C. Carreras, "Women in Physics in Spain: Changes Since 2002," in Women in Physics, 2nd IUPAP International Conference, AIP Conference Proceedings 795, New York: American Institute of Physics, 2005, pp.159-160 [http://proceedings.aip.org/proceedings/confproceed/795.jsp].

3. Ministry of Education and Science, Estadisticas [www.mec.es].

4. Secretaría General. Subdirección General de Recursos Humanos, Informe Mujeres Investigadoras, Madrid: Consejo Superior Investigaciones Cientifica, 2007. 